\title{
Meshing Condition and Kinematic Properties of non-circular Gear
}

\author{
Silvia Medvecká-Beňová1,*
}

${ }^{1}$ Technical University of Košice, Faculty of Mechanical Engineering, Department of Construction, Automotive and Transport Engineering, Letná 9, Košice

\begin{abstract}
The gearing with changing transmission gear ratio are used in the practice, even though the "standard" gearing with constant transmission gear ratio are used more often. The article examines the mesh conditions proposed in elliptical gears, as I speed and power ratios in this proposed gearings. The work is devoted to the analysis of these kinematic conditions in the proposed gearings and examines their differences from "standard" ring gear transmission with a constant transference number. The problem is solved for elliptical, eccentric gear with a continuously variable gear ratio to a range from 0.5 through 1 to 2 .
\end{abstract}

Keywords: non-circular gear; elliptical gear; variable transmission; kinematic properties.

\section{Introduction}

Gearing is a phenomenon of our culture as well as his wheel and circular motion. The history of gears is probably as old as civilization itself. The earliest description of gears was written in the 4th century B.C. by Aristotle. He wrote that the "direction of rotation is reversed when one gear wheel drives another gear wheel". In the 3rd century B.C., various Greek Inventors used gears in water wheels and clocks, and sketches of various types of gears of around this time were found in Leonardo da Vinci's notebooks later on.

The idea of non-circular gears originates from the precursors of the engineering thought. These gears were sketched by Leonardo da Vinci, and found their application in many types of mechanical devices, like locks and toys. In late XIX, century Franz Reuleaux ordered at Gustav Voigt Mechanische Werkstatt in Berlin a series of non-circular gear models to help study kinematics. The gears made at those times had simplified tooth shapes and, for this reason, the meshing conditions were not always correct [9].

A common challenge in the design of mechanical systems is the kinematic synthesis of a mechanism in order to satisfy a set of motion characteristics [4]. Frequent requirements are to guide a rigid body through a series of specified positions and orientations (rigid body guidance), to force a coupler point to move along a prescribed trajectory (path generation), or to cause an output member to move according to a specific function of the input motion (function generation) [8].

The first step in the noncircular gears virtual design process is the generation of the conjugate pitch curves, starting from a predesigned law of motion for the driven element or a predesigned geometry for the driving gear pitch curve.

By designing a pair of non-circular gears, which are able to perform a proper gear ratio function, the output member of a mechanism can be effectively forced to move according to a prescribed law of motion, when operated at a constant input- 
velocity. This mechanism is designed to obtain a specific motion law. Detailed knowledge of meshing conditions is a prerequisite for studying kinematic conditions in gearings, as well as the strength calculation of gearing.

\section{Characteristic of non-circular gear}

Generation of this noncircular gear was by developed starting from the hypothesis such as the law of driven gear motion, variation of gear transmission ratio and design of driving gear pitch curve. This model of non-circular gear was by designed for variable transmission in the range $\mathrm{u}=0.5$ to 2.0 . This transfer should be formed by two identical wheels with the number of teeth $\mathrm{z}_{1}=\mathrm{z}_{2}=24$ and gearing module $\mathrm{m}_{\mathrm{n}}=3.75 \mathrm{~mm}$, the distance $\mathrm{a}=90 \mathrm{~mm}$ and for $\mathrm{a}$ one direction of rotation.

Given that each gear must satisfy the conditions of proper meshing, it was necessary to determine the geometric shape of the wheels. The pitch curve corresponded to pitch circles in regular gears. They represent a non-circular gear as two rollers rolling together without slip, provided there, is no addendum modification and the nominal axle distance is used.

The gearing is designed such that the pitch curve is composed of an ellipse formed with the basic parameters shown in Fig. 1. A geometric center of the gear is not the center of wheel's rotation. The center of gear's rotation is in the focus point of the ellipse.

Circle with the diameter of $90 \mathrm{~mm}$

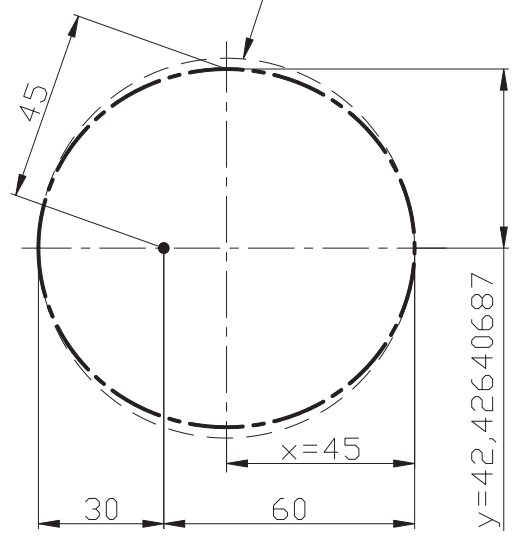

Fig. 1: Dimensions of a pitch ellipse.
The pitch ellipse has a large half-axis $\mathrm{x}=45 \mathrm{~mm}$, which is half of the axial distance. The second half-axis is determined by the distance from the focus point $45 \mathrm{~mm}$ (Figure 1), whose position is determined by considering the desired gear ratio.

The procedure of creating the gear is analyzed in detail in the literature [6]. The gears for a given variable transmission have been proposed as elliptical - eccentrically placed (Figure 2), so that conditions were right shot.

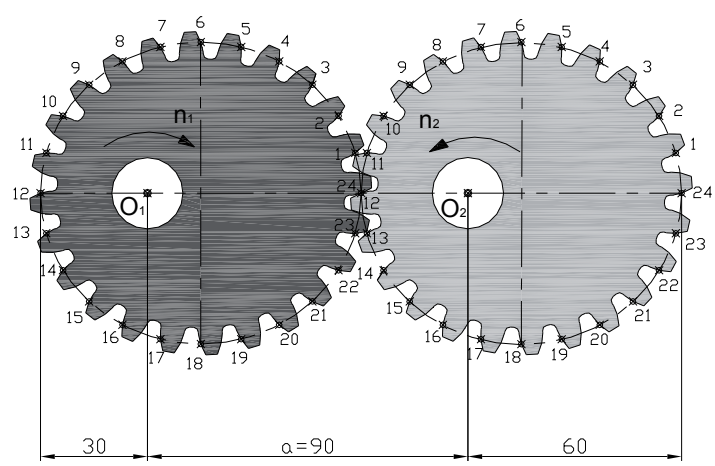

Fig. 2: Designed non-circular (elliptical) gear.

\section{Meshing Condition of Elliptical gearing}

Involute gear is characterized by rectilinear pressure line. This is true even for the designed elliptical gearing. The result of examination for teeth $24-12$ in meshing is shown in Figure 3.

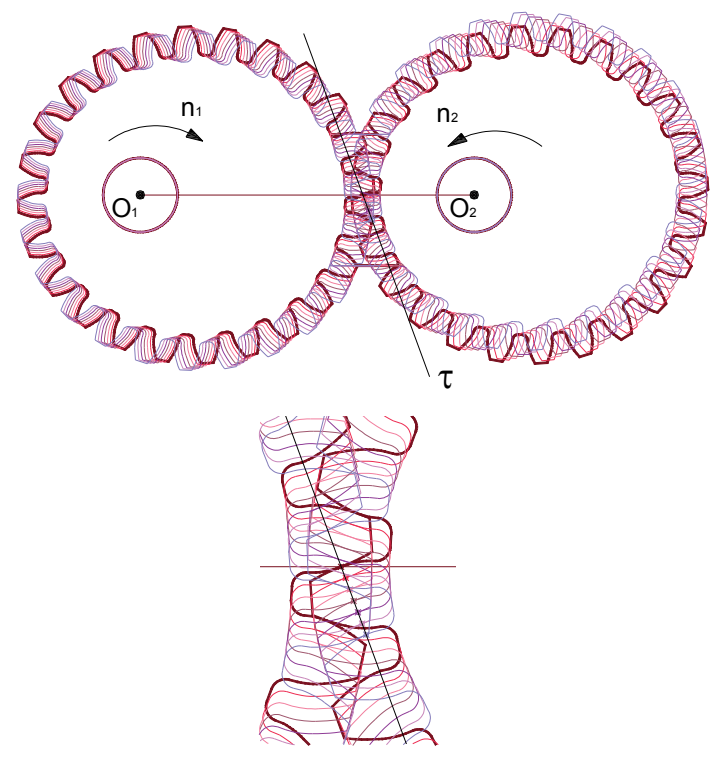

Fig. 3: Face of pressure line. 
The characteristic points $\mathrm{A}, \mathrm{E}$ are the end points of the meshing line $\mathrm{AE}$, which is component of pressure line $\tau$, in the meshing line is realize meshing of teeth of gearing.

The length of meshing line for spur gears is calculated by equation (1).

$$
\begin{aligned}
\overline{A E} & =\sqrt{r_{a 1}^{2}-r_{b 1}^{2}}+\sqrt{r_{a 2}^{2}-r_{b 2}^{2}}- \\
& -a \cdot \sin \alpha(m m)
\end{aligned}
$$

where $\mathrm{r}_{\mathrm{a} 1,2}$ is radius of addendum circle, $\mathrm{r}_{\mathrm{b} 1,2}$ is radius of base circle, a is axial distance and $\alpha$ is pressure angle.

The expression of meshing properties is used coefficient of meshing $\varepsilon \alpha$, calculate by equation (2).

$$
\varepsilon_{\alpha}=\frac{\overline{A E}}{p_{t b}}
$$

where ptb is base pitch. The value of the coefficient of meshing for spur gears with straight teeth is in the range $1<\varepsilon_{\alpha}<2$.

The length of meshing line of designed eccentrically elliptical gearing cannot calculate by equation for the circular involute gearing. Therefore, they are intended of graphic for each pair of teeth of meshing (for example Figure 4 and Figure 5).

The value of length of meshing line $\mathrm{AE}$ and coefficient of meshing $\varepsilon \alpha$ for elliptical and spur gearing are shows in Table 1.

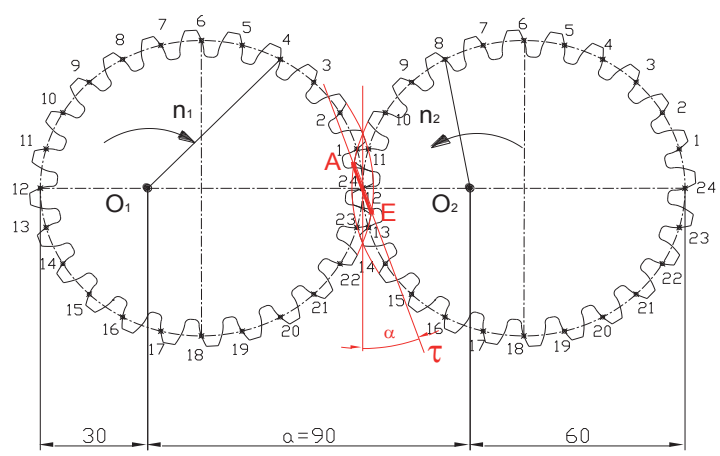

Fig. 4: The meshing line AE for teeth 24 - 12 in meshing.

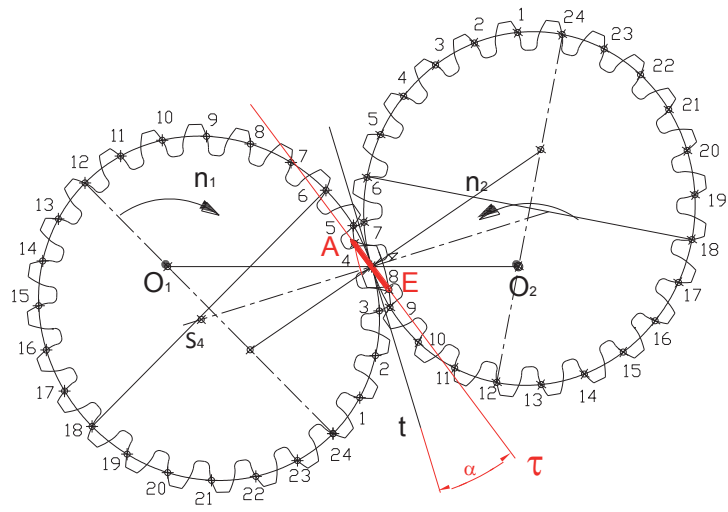

\begin{tabular}{|c|c|c|c|c|c|c|c|}
\hline \multicolumn{3}{|c|}{ Elliptical gearing } & \multicolumn{5}{|c|}{ Spur gearing $\left(\mathrm{m}_{\mathrm{n}}=3,75 \mathrm{~mm}\right)$} \\
\hline $\begin{array}{l}\text { Meshing teeth } \\
\text { input - output }\end{array}$ & $A E(m m)$ & $\varepsilon_{a}$ & $r_{1-i}(m m)$ & $r_{2-j}(\mathrm{~mm})$ & $\begin{array}{c}\text { Transmission ratio } \\
u_{i}=r_{2} / r_{1}\end{array}$ & $A E(m m)$ & $\varepsilon_{a}$ \\
\hline $24-12$ & 14.406 & 1.222 & 60 & 30 & 0.5 & 17.527 & 1.488 \\
\hline $01-11$ & 14.412 & 1.223 & 59.458 & 30.541 & 0.5136 & 17.542 & 1.489 \\
\hline $02-10$ & 14.436 & 1.225 & 57.891 & 32.108 & 0.5546 & 17.583 & 1.492 \\
\hline $03-9$ & 14.503 & 1.231 & 55.449 & 34.550 & 0.6230 & 17.636 & 1.497 \\
\hline $04-8$ & 14.52 & 1.232 & 52.338 & 37.663 & 0.7196 & 17.686 & 1.501 \\
\hline $05-7$ & 14.548 & 1.235 & 48.779 & 41.221 & 0.8450 & 17.721 & 1.504 \\
\hline $26-6$ & 14.594 & 1.239 & 45 & 45 & 1 & 18.235 & 1.647 \\
\hline
\end{tabular}

Fig. 5: The meshing line AE for teeth $4-8$ in meshing.

Table 1: Length of the meshing line AE and coefficient of meshing Ea.

Designed elliptical gearing has a the greatest Therefore, the length of the meshing line $\mathrm{AE}$ and value of meshing line AE for a pair of teeth, which in meshing have a gear ratio $\mathrm{u}=1.0$. The designed elliptical gearing is characterized in that the gearing coefficient of meshing $\varepsilon \alpha$ for each pair of teeth in meshing are not constant, as in a standard circular spur gear.

is comprised by teeth with different profiles.

Detailed knowledge of meshing condition is 
a prerequisite not only for solving deformation of gearing, but also for the strength calculation of gearing. The involute gear is characterized by rectilinear pressure line. The length of meshing line is the same for the all gearing in the standard circular involute gearing. The length of the meshing line and coefficient of meshing for each pair of teeth in meshing are not constant for designed elliptical gearing with variable gear ratio.

\section{Kinematic Properties of Elliptical gearing}

In pursuit of kinematic ratios on the proposed gearings we assume from the right mesh conditions. Kinematic conditions were processed for a gear 1 (the center of rotation at point $\mathrm{O}_{1}$ ) and the gear 2 (with the center of rotation at point $\mathrm{O}_{2}$ ). The two gears are shown in a kinematic dependence one graph (on the horizontal axis of the wheel teeth first).

In Figure 6 is a course of continuously changing gear ratio in one mesh generated by elliptical gear, which continuously varies in the range from $\mathrm{u}=0.5$ through $\mathrm{u}=1.0$ until $\mathrm{u}=2.0$ and back. Thus the gear ratio changes over the time of one revolution. A gear ratio value that is less than 1.0 signifies that this is an overdrive, and a gear ratio value greater than 1.0 signifies a speed reduction.

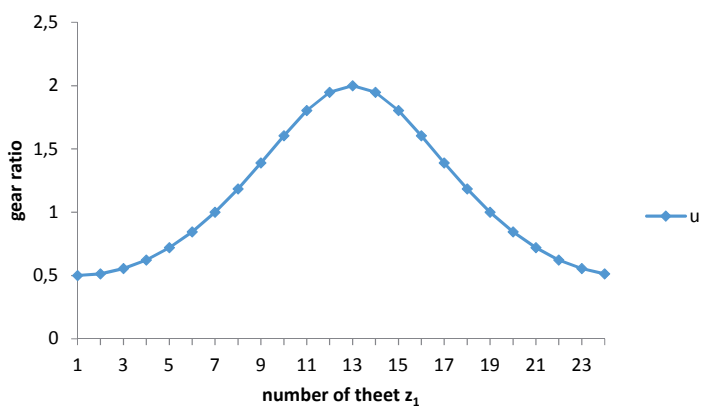

Fig. 6: Changing transmission ratio.

The rotational speed on the drive wheel gear and the driven wheel gear is constant to standard spur gears. For designed elliptical gearing with variable transmission, the angular velocity of the driven wheel is not constant but is changed according to the continuous changing of the gear ratio. This is shown in Figure 7, if the angular velocity is on the drive wheel $\left(\omega_{1}=100 \mathrm{~s}^{-1}\right)$ and the driven elliptical wheel $\left(\omega_{2 \mathrm{i}}\right)$.

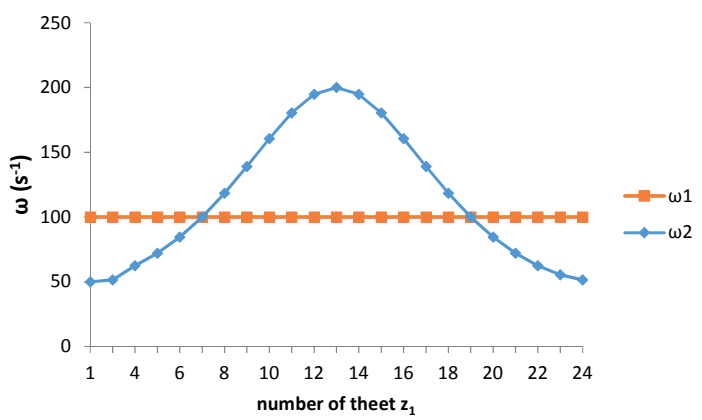

Fig. 7: Rotational speed.

The movement of spur gear is defined in the face plane, therefore kinematics of this motion is planar The points of gear are moved along a circular path at a circumferential velocity at the image central point $\mathrm{C}$ determined by equation (3).

$v=v_{1}=v_{2}=r_{1} \cdot \omega_{1}=-r_{2} \cdot \omega_{2}$

where $\mathbf{r}_{1,2}$ is radius of pitch circle, $\omega_{1,2}$ is a rotational speed.

The speed condition of meshing for teeth 4 (driver) and 8 (drive wheel) in the central point are shown in Figure 8.

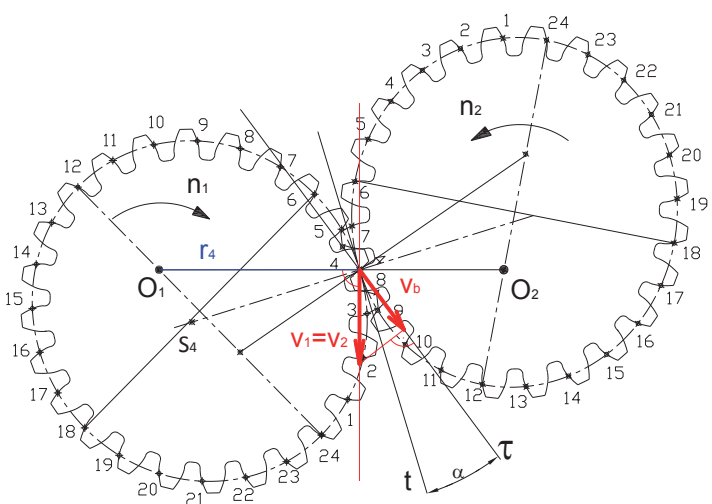

Fig. 8: Circumferential velocity for teeth $4-8$ in meshing in the central point.

Circumferential velocity in the central points for the pairs of teeth in meshing is not a constant but changes continuously, depending on the number of gear ratio (Figure 9).

In the central points are the sizes of circumferential velocities measurement for each pair teeth in meshing are different in the designed elliptical gearing. 
Table 2: Circumferential velocity and rotational speed for the central points of the teeth for $\omega_{1}=100 \mathrm{~s}^{-1}$

\begin{tabular}{|c|c|c|c|c|c|}
\hline \multirow{2}{*}{$\begin{array}{l}\text { Meshing teeth } \\
\text { input - output }\end{array}$} & \multicolumn{2}{|c|}{ Radius of mesh points } & \multirow{2}{*}{$\begin{array}{l}\text { Transmission ratio } \\
\qquad \mathbf{U}_{\mathrm{i}}=\mathbf{r}_{2-\mathrm{j}} / \mathbf{r}_{1-\mathrm{i}}\end{array}$} & \multirow{2}{*}{$\begin{array}{c}\text { Rotational speed } \\
\omega_{2 i}=\omega_{1} / u_{i}\left(s^{-1}\right)\end{array}$} & \multirow{2}{*}{$\begin{array}{c}\text { Circumferential velocity } \\
\qquad \mathbf{v}_{1-\mathrm{i}}=\mathbf{v}_{2-\mathrm{j}}\left(\mathrm{m} . \mathrm{s}^{-1}\right)\end{array}$} \\
\hline & $r_{1-i}(m m)$ & $\mathbf{r}_{2-j}(\mathbf{m m})$ & & & \\
\hline $24-12$ & 60.000 & 30.000 & 0.500 & 200.000 & 6.000 \\
\hline $01-11$ & 59.459 & 30.541 & 0.514 & 194.704 & 5.946 \\
\hline $02-10$ & 57.892 & 32.108 & 0.555 & 180.310 & 5.789 \\
\hline $03-9$ & 55.450 & 34.550 & 0.623 & 160.514 & 5.545 \\
\hline $04-8$ & 52.337 & 37.663 & 0.720 & 138.966 & 5.234 \\
\hline $05-7$ & 48.779 & 41.221 & 0.845 & 118.343 & 4.878 \\
\hline $26-6$ & 45.000 & 45.000 & 1.000 & 100.000 & 4.500 \\
\hline $07-5$ & 41.221 & 48.779 & 1.183 & 84.509 & 4.122 \\
\hline $08-4$ & 37.663 & 52.337 & 1.390 & 71.963 & 3.766 \\
\hline $09-3$ & 34.550 & 55.450 & 1.605 & 62.313 & 3.455 \\
\hline $10-2$ & 32.108 & 57.892 & 1.803 & 55.463 & 3.211 \\
\hline $11-1$ & 30.541 & 59.459 & 1.947 & 51.366 & 3.054 \\
\hline $12-24$ & 30.000 & 60.000 & 2.000 & 50.000 & 3.000 \\
\hline $13-23$ & 30.541 & 59.459 & 1.947 & 51.366 & 3.054 \\
\hline $14-22$ & 32.108 & 57.892 & 1.803 & 55.463 & 3.211 \\
\hline $15-21$ & 34.550 & 55.450 & 1.605 & 62.313 & 3.455 \\
\hline $16-20$ & 37.663 & 52.337 & 1.390 & 71.963 & 3.766 \\
\hline $17-19$ & 41.221 & 48.779 & 1.183 & 84.509 & 4.122 \\
\hline $18-18$ & 45.000 & 45.000 & 1.000 & 100.000 & 4.500 \\
\hline $19-17$ & 48.779 & 41.221 & 0.845 & 118.343 & 4.878 \\
\hline $20-16$ & 52.337 & 37.663 & 0.720 & 138.966 & 5.234 \\
\hline $21-15$ & 55.450 & 34.550 & 0.623 & 160.514 & 5.545 \\
\hline $22-14$ & 57.892 & 32.108 & 0.555 & 180.310 & 5.789 \\
\hline $23-13$ & 59.459 & 30.541 & 0.514 & 194.704 & 5.946 \\
\hline
\end{tabular}

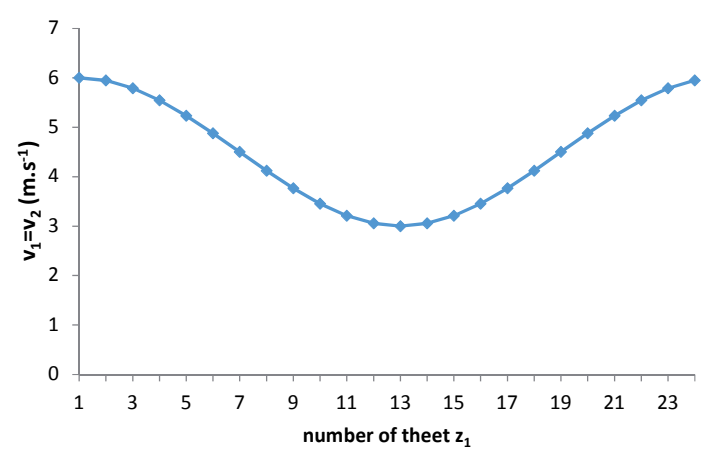

Fig. 9: Circumferential velocity in the central point.

\section{Conclusions}

Noncircular gears are presented as a curiosity for the gear industry history, due to their complex design and manufacturing difficulties. Nowadays, performant modelling and simulation softwares, advanced CNC machine tools and nonconventional manufacturing technologies enable noncircular gear design and manufacture to be more feasible.

The main objective of this paper was to defined base kinematic properties of non-circular gear. Gearing was designed to meet continuous change of gear ratio during one rotation. The gearing consists of two identical gears and the basic shape of the gear wheel is formed by an ellipse. Wheels are designed for only one direction of rotation and the center of rotation is one of the foci of ellipse. It is the gearing with variable transmission. Properties of this gearing are different from the properties of standard circular gears - spur gear. 
Thus the gear ratio changes over the time of one revolution. A gear ratio value that is less than 1.0 signifies that this is an overdrive, and a gear ratio value greater than 1.0 signifies a speed reduction. For designed elliptical gearing with variable transmission, the angular velocity of the driven wheel is not constant but is changed according to the continuous changing of the gear ratio. Also the circumferential velocity in the central points for the pairs of teeth in meshing is not a constant but changes continuously, depending on the number of gear ratio. This elliptical gearing was by used in the drive mechanism for a new press for example. The new press kinematics result in a reduced pressure dwell time in comparison with a conventional press kinematic.

\section{Acknowledgements}

This paper was written in the framework of Grant Project VEGA: "1/0197/14 - Research of the new methods and innovative design solutions to increase efficiency and to reduce emissions of a vehicle drive unit with an assessment of the potential operational risks".

\section{References and Notes}

[1] Czech, P., Wojnar, G., Warczek, J. (2014). Diagnozowanie uszkodzeń wtryskiwaczy w silnikach spalinowych pojazdów przy użyciu analizy bispektrum i radialnych sieci neuronowych. Logistyka, 3, 1181-1187

[2] Doege E., Meinen J., Neumaier T., Schaprian M. (2001). Numerical design of a new forging press drive incorporating non-circular gears. Journal of Engineering Manufacture, 215, 467-471.

[3] Femandez del Rincon, A., Viadero, F, et al. (2013). A model for the study of meshing stiffness in spur gear transmissions. Mechanism and Machine Theory, 61, 30-58.

[4] Litvin F. L. et al. (2008). Design and investigation of gear drives with non-circular gears applied for speed variation and generation of functions. Computer Methods in Applied Mechanics and Engineering, 197, 3783-3802.

[5] Medvecká_Beňová, S. (2015). Deformation and stiffness of spur gear teeth and trheir influence on gear noise. Scientific Journal of Silesian University of Technology: Series Transport, 89, 101-107.

[6] Medvecká_Beňová, S., Vojtková, J. (2014). Aplication of asymetric profile in gearing in gearings with eccentric gears Zeszyty naukowe Politechniki Śląskiej, 85, 1925, 89-93.

[7] Sapieta, M., Dekýš, V., Pastorek, P. (2014). Using of activ thermography and lock-in method with ultrasound exication for detection of material defect. Zeszyty naukowe Politechniki Śląskiej, 84, 1907, 119-124
[8] Tong S.-H., Yang D. C. H. (1998). Generation of identical noncircular pitch curves. Journal of mechanical design, 120, 337-341.

[9] Zarebski I., Sałacinski T. (2007). Designing and WEDM manufacturing of non-circular gears. Zbiór referatów na miedzynarodowa konferencje naukowo-techniczna. Warszawa.

\section{Biographical notes}

Silvia Medvecká-Beňová, doc. Ing. PhD., she received M.S. degree from the Technical University of Košice in 1997, PhD. degree received in Machine Parts and Mechanisms from the Technical University of Košice in 2002. She is an associated professor of the Department of Construction, Automotive and Transport Engineering of the Faculty of Mechanical Engineering, Technical University of Košice. Her research interests include stiffness and deformation of gearing, noise of gearbox, stress of gearing, gears with a continuous change of speed ratio. 